\title{
Comparative Studies of Dynamic Mechanical Properties of Desert Sand Concrete and Ordinary Concrete
}

\author{
Qiaoli Chen $\mathbb{D D}^{1,2}$ Haifeng Liu $\mathbb{D}^{1},{ }^{1}$ Li Han, ${ }^{3}$ and Yiying Wang ${ }^{4}$ \\ ${ }^{1}$ College of Civil and Hydraulic Engineering, Ningxia University, Yinchuan 750021, China \\ ${ }^{2}$ Ningxia Center for Research on Earthquake Protection and Disaster Mitigation in Civil Engineering, Yinchuan 750021, China \\ ${ }^{3}$ Yinchuan University of Energy, Yinchuan 750100, China \\ ${ }^{4}$ School of Transportation, Inner Mongolia University, Inner Mongolia 010021, China \\ Correspondence should be addressed to Qiaoli Chen; chenqiaoli9110@163.com and Haifeng Liu; liuhaifeng1557@163.com
}

Received 11 November 2021; Accepted 20 January 2022; Published 10 February 2022

Academic Editor: Shaofeng Wang

Copyright ( $\odot 2022$ Qiaoli Chen et al. This is an open access article distributed under the Creative Commons Attribution License, which permits unrestricted use, distribution, and reproduction in any medium, provided the original work is properly cited.

\begin{abstract}
Ningxia is located in the western part of China, which abounds with desert resources. The application of desert sand in concrete has not been fully studied. In order to study the failure mechanism of desert sand concrete under impact loading, dynamic impact experiments on desert sand concrete and ordinary concrete were carried out by using the $74 \mathrm{~mm}$ diameter split Hopkinson pressure bar (SHPB) experimental apparatus. The dynamic mechanical properties of desert sand concrete under different impact velocities were analyzed. The random distribution program of round coarse aggregate in desert sand concrete was designed to generate the random distribution of coarse aggregate by ANSYS/APDL language. The dynamic failure process of single-graded concrete and two-graded concrete was numerically simulated and compared. The results showed that desert sand concrete and ordinary concrete have obvious rate-dependent effect. Detailedly, the ordinary concrete is totally destroyed when impact velocity is $10 \mathrm{~m} / \mathrm{s}$, but the desert sand concrete still maintains the cone shape at impact velocity of $18 \mathrm{~m} / \mathrm{s}$, which indicates that the impact resistance of desert sand concrete is better than that of ordinary concrete. When impact velocity is $5 \mathrm{~m} / \mathrm{s}$, the single-graded concrete and two-graded concrete are both destroyed, but the desert sand concrete is not damaged. When impact velocity is $10 \mathrm{~m} /$ $\mathrm{s}$, the dynamic failure mode of single-graded concrete, two-graded concrete, and desert sand concrete is basically the same. When impact velocity is $15 \mathrm{~m} / \mathrm{s}$, the single-grade concrete shows different dynamic failure mode from that of desert sand concrete and two-graded concrete.
\end{abstract}

\section{Introduction}

Concrete is commonly used in civil engineering material. For better understanding of concrete, many researchers are devoted to studying the properties of concrete materials and concrete structures [1-5]. For four-component ordinary concrete, fine aggregate and coarse aggregate account for $70 \%$ to $80 \%$ of the volume of concrete [6], which plays the role of structural frame of concrete. However, the mining of fine aggregate and coarse aggregate has a tremendous impact on surrounding environment. Therefore, it is important to seek substitutes for fine aggregate and coarse aggregate and make efforts to produce high-quality concrete. Ningxia is located in inland area of northwest China and surrounded by desert on three sides, being rich in desert sand resources. The application of desert sand as medium sand in concrete for engineering can not only reduce the burden of environment, but also have the advantages of making use of local materials and reducing engineering cost. At present, many researchers have carried out studies on the engineering properties of desert sand concrete [7-18], but research on its dynamic mechanical properties has just started. Besides, there are no corresponding national specifications for desert sand application in concrete as fine aggregate [19]. Therefore, improving the ability of concrete structures to resist dynamic loading such as earthquakes, shocks, and explosions is a burning issue tracked by domestic and foreign researchers. For example, Abrams [20] first discovered the 
rate sensitivity of dynamic compressive strength of concrete. Besides, Jones [21] carried out an experimental study on the relationship between loading rate and compressive strength of concrete, which becomes another milestone for the development of dynamic mechanical properties of concrete. In addition, Sparks and Menzies [22] used the dynamic loading test of cylindrical specimens to prove the rate sensitivity of concrete. In 1993, HJC constitutive model was proposed by Holmquist et al. [23], who believed that the damage was mainly brought about by the accumulation of equivalent plastic strain. In the past years, researchers usually used the dropping impact hammer to carry out the concrete impact experiments, in which the stress-strain curve could not be obtained because the inertial effect was neglected. However, the SHPB experimental technology can overcome this difficulty and thus becomes the most commonly method to explore the dynamic mechanical properties of concrete at present. The initial prototype of SHPB (split Hopkinson pressure bar) apparatus was proposed by Hopkinson [24], which made a big breakthrough in the study of dynamic properties of brittle materials such as concrete [25-28] after improving. For instance, Hu et al. [29, 30] made great efforts on the dynamic mechanics of concrete by SHPB technology. Besides, Lv and Song [31] used a large-scale hydraulic servo static and dynamic universal test machine to perform the dynamic compressive experiment of concrete. In addition, Zhang and $\mathrm{Li}$ [32] proposed a method for selecting material parameters of HJC model. Furthermore, Ning et al. [33-37] carried out a lot of experiments to study the properties of concrete under impact loading. Apart for experimental studies, many researchers simulated the dynamic mechanical properties of concrete by numerical simulation [38-40].

Aggregate particles with a size of more than $4.75 \mathrm{~mm}$ in concrete are called coarse aggregate, and the grain composition of coarse aggregate directly affects the mechanical properties of concrete [41]. At present, a lot of research has been conducted on the mechanical properties of singlegraded concrete, but few studies are carried out on multigraded concrete. The difference between single-graded concrete and multi-graded concrete lies in whether one or more continuous graded stones are directly mixed in the concrete. Based on the review of previous research [42, 43], a new study to obtain the dynamic characteristics of ordinary concrete and desert sand concrete is conducted in this paper. The finite element analysis software ANSYS/LS-DYNA was utilized to simulate the single-graded concrete and twograded concrete under impact loading, and the dynamic failure process was simulated to reveal the dynamic failure mechanism of desert sand concrete. The experimental results provide a guiding significance for the popularization of concrete and a theoretical basis for the application of desert sand concrete in civil engineering and hydraulic engineering.

\section{Experimental Investigations}

2.1. Test Setup. SHPB apparatus has been one of the main experimental setups for testing dynamic mechanical properties of concrete specimens. In the present study, a $74 \mathrm{~mm}$ diameter SHPB experimental apparatus is used to obtain the dynamic properties of desert sand concrete and ordinary concrete, in which one dimension and uniformity hypotheses are applied. The experiments were carried out in Shanxi Key Laboratory of Material Strength and Structural Impact, Taiyuan University of Technology.

As shown in Figure 1, the specimens are clamped between the incident bar and the transmitted bar. First, the launcher shoots the bullet to impact the incident bar, and the incident bar impacts the specimens. Then, incident wave and reflected wave will be obtained by the strain gauge on the pressure bar. Because wave impedance is different between specimens and incident bar, part of the incident wave will be reflected, forming a reflected wave that will be obtained by the strain gauge on the incident bar. The other part of the incident wave passes through the specimens into the transmitted bar and becomes the transmitted wave which will be obtained by the strain gauge on the transmitted bar. In order to obtain the effective data in SHPB test, the tests need to reach the stress equilibrium state; i.e., all data in the test meet the requirement that the sum of the incident and reflected stress wave coincides with the transmitted stress wave.

2.2. Test Specimens. In the test, ordinary medium sand in concrete is substituted partly or completely by desert sand. $\mathrm{Mu}$ Us desert sand is obtained from Yanchi County, Ningxia Hui Autonomous Region. The physical performance index of $\mathrm{Mu}$ Us desert sand is listed in Table 1. The result of sieve analysis of $\mathrm{Mu}$ Us desert sand is shown in Table 2, and its chemical composition is given in Table 3 . It can be seen that $\mathrm{Mu}$ Us desert sand belongs to extra-fine sand. For comparison purpose, the chemical composition of ordinary sand in concrete is also listed in Table 3. It can be seen that the $\mathrm{SiO}_{2}$ content of $\mathrm{Mu}$ Us desert sand is similar to that of ordinary sand. Reference [10] carried out a test of mortar and concrete made of $\mathrm{Mu}$ Us desert sand, and the results indicated that the Mu Us desert sand can be used as engineering sand.

In order to study the influence of desert sand on the mechanical properties of concrete, the dynamic compression experiments on concrete made of desert sand were carried out. Two groups of specimens denoted as M1 and M6 were made. For comparison purposes, the ordinary concrete specimens prepared were denoted as OC. The mix ratio of OC was determined by Specification for Mix Proportion Design of Ordinary Concrete [44], and the compositions of the concrete phase of specimens are listed in Table 4 . The type of Portland cement was $425^{\#}$ (branded as Saima). The coarse aggregate was artificial gravel, and fine aggregate was artificial sand washing, both produced in Zhenbeipu of Ningxia. In the SHPB test, in order to eliminate the influence of friction and inertial force on the specimen, it is necessary to control the aspect ratio of the specimen. Gray [45] suggested that the aspect ratio of the specimen should be in the range of $0.5 \sim 1.0$. Therefore, the specimens were designed as $74 \mathrm{~mm}$ diameter and $70 \mathrm{~mm}$ height cylinders. After demolding, the specimens were wet-cured in the laboratory 


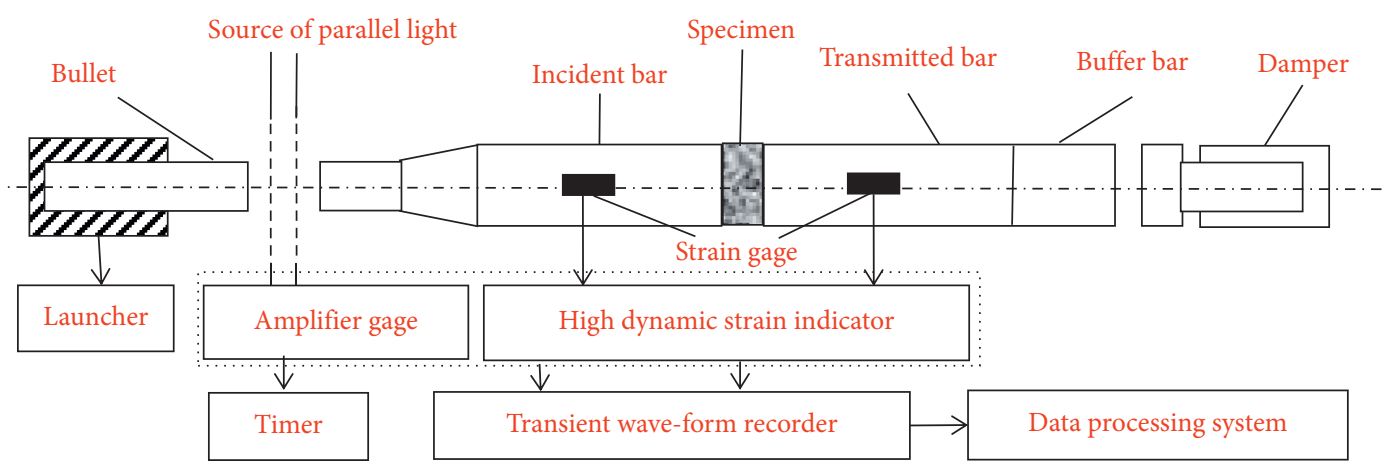

FIGURE 1: Schematic of SHPB experimental apparatus.

TABle 1: Physical performance index of Mu Us desert sand.

\begin{tabular}{lccccc}
\hline Index & Apparent density $\left(\mathrm{kg} \cdot \mathrm{m}^{-3}\right)$ & Bulk density $\left(\mathrm{kg} \cdot \mathrm{m}^{-3}\right)$ & Porosity (\%) & Mud content (\%) & Fineness modulus (\%) \\
\hline Measured values & 2624 & 1400 & 40.95 & 0.14 & 0.194 \\
\hline
\end{tabular}

TABLE 2: Sieve analysis of Mu Us desert sand.

\begin{tabular}{|c|c|c|c|c|c|c|c|}
\hline Size of sieve $(\mathrm{mm})$ & 0.600 & 0.300 & 0.150 & 0.097 & 0.075 & 0.050 & $<0.050$ \\
\hline Sieve residues (\%) & 0.20 & 2.46 & 13.88 & 47.19 & 28.26 & 7.26 & 0.26 \\
\hline Quality grading (g) & 1.00 & 12.30 & 69.40 & 236.00 & 141.30 & 36.30 & 1.30 \\
\hline Accumulated sieve residues (\%) & 0.20 & 2.66 & 16.54 & 63.73 & 91.99 & 99.25 & 99.51 \\
\hline
\end{tabular}

TABle 3: Chemical composition of Mu Us desert sand.

\begin{tabular}{lcccccccc}
\hline Ingredient & $\mathrm{SiO}_{2}$ & $\mathrm{FeO}$ & $\mathrm{Al}_{2} \mathrm{O}_{3}$ & $\mathrm{CaO}$ & $\mathrm{MgO}$ & $\mathrm{K}_{2} \mathrm{O}$ & $\mathrm{Na}_{2} \mathrm{O}$ & Loss on ignition (\%) \\
\hline Desert sand & 82.66 & 1.85 & 8.72 & 2.00 & 1.51 & 0.12 & 0.07 & 2.9 \\
Ordinary sand & 86.55 & 0.98 & 9.74 & 0.96 & 1.09 & - & - & - \\
\hline
\end{tabular}

TABLE 4: Mix ratio of concrete.

\begin{tabular}{lcccccccc}
\hline Specimen & $\begin{array}{c}\text { Desert sand } \\
\text { replacement ratio } \\
(\%)\end{array}$ & $\begin{array}{c}\text { Water } \\
\left(\mathrm{kg} \cdot \mathrm{m}^{-3}\right)\end{array}$ & $\begin{array}{c}\text { Cement } \\
\left(\mathrm{kg} \cdot \mathrm{m}^{-3}\right)\end{array}$ & $\begin{array}{c}\text { Fly ash } \\
\left(\mathrm{kg} \cdot \mathrm{m}^{-3}\right)\end{array}$ & $\begin{array}{c}\text { Medium sand } \\
\left(\mathrm{kg} \cdot \mathrm{m}^{-3}\right)\end{array}$ & $\begin{array}{c}\text { Water reducing } \\
\text { agent }\left(\mathrm{kg} \cdot \mathrm{m}^{-3}\right)\end{array}$ & $\begin{array}{c}\text { Aggregate } \\
\left(\mathrm{kg} \cdot \mathrm{m}^{-3}\right)\end{array}$ & $\begin{array}{c}\text { Desert sand } \\
\left(\mathrm{kg} \cdot \mathrm{m}^{-3}\right)\end{array}$ \\
\hline M1 & 0 & 190 & 475 & 52 & 609 & 1.58 & 1127 \\
M6 & 100 & 190 & 475 & 52 & 0 & 2.90 & 0 & 1127 \\
OC & - & 125 & 300 & 50 & 300 & 2.5 & 500 & - \\
\hline
\end{tabular}

until being tested. The two surfaces of the specimens were ground to ensure nonparallelism of the two surfaces, to be no more than $0.02 \mathrm{~mm}$ after 28 days' curing.

To guarantee the reliability of the experiment results, 6 concrete specimens were made under each impact velocity according to the standard of concrete specimens making. The desert sand concrete specimens and ordinary concrete specimens are shown in Figures 2(a) and 2(b), respectively, and the experimental specimen after grinding is presented in Figure 2(c). It can be seen that the surface color of desert sand concrete specimen is different from that of ordinary concrete specimen, which can be explained by the different composition and formation location of sands. The desert sand has no scouring effect of running water, which can retain some nutrients, while the river sand is just the opposite.
2.3. Experimental Results and Analysis. Figures 3(a) and 3(b) show the original waveform of desert sand concrete at different strain rates obtained by SHPB. It can be seen that under the same strain rate, there is no significant difference between the voltage-time curves of concrete specimens M1 and M6 except for amplitudes.

"Two-wave" and "three-wave" method are usually used to process SHPB data after the incident wave, reflected wave, and transmitted wave are obtained through experiments $[46,47]$. In order to reduce the insensitivity of the strain gauge and the error of resistance, $K$ value needs to be calibrated by hitting the incident bar without adding the specimen. The calibrated $K$ value is the ratio of strain $\varepsilon$ to voltage $U$ which is measured by the high dynamic strain indicator. The stress $\sigma$, strain $\varepsilon$, and $K$ value are determined by the following equations: 


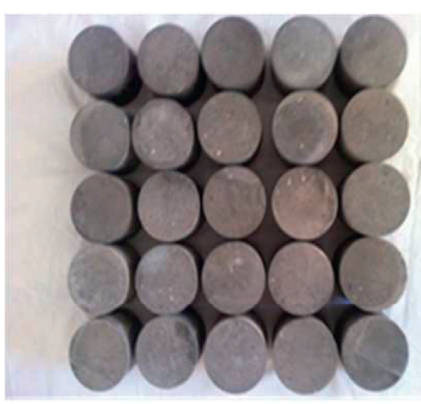

(a)

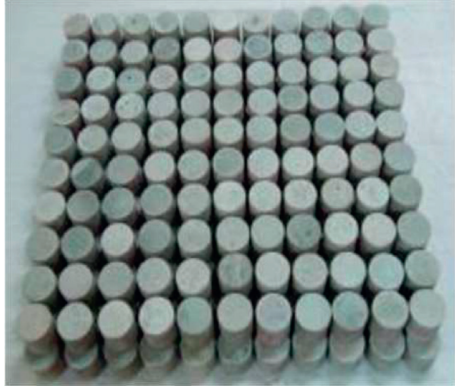

(b)

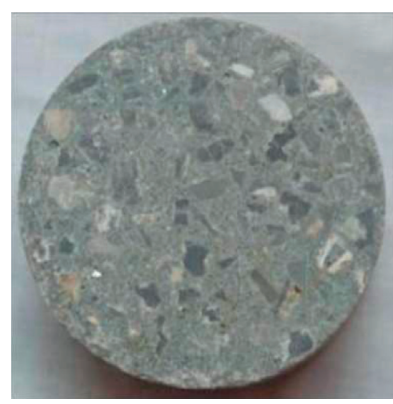

(c)

Figure 2: Concrete specimens (74 mm diameter, $70 \mathrm{~mm}$ height cylinder). (a) Specimens of desert sand concrete. (b) Specimens of ordinary concrete. (c) Specimens after grinding.

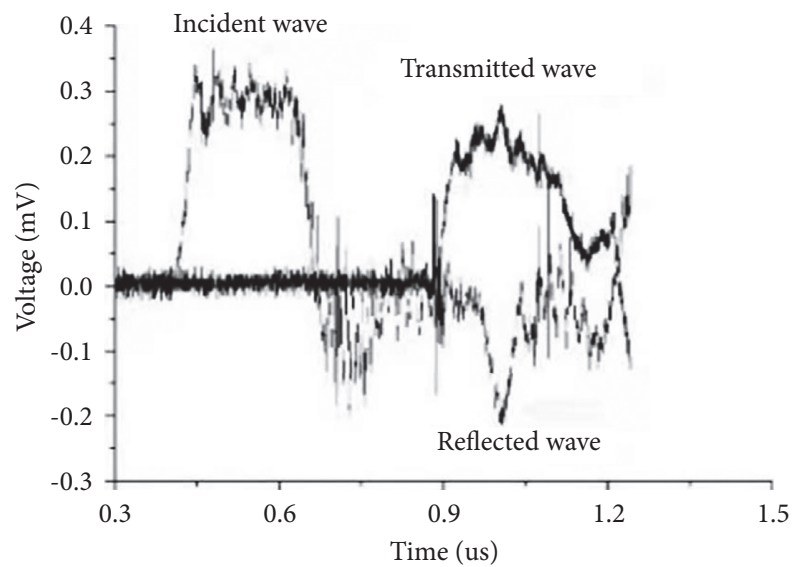

(a)

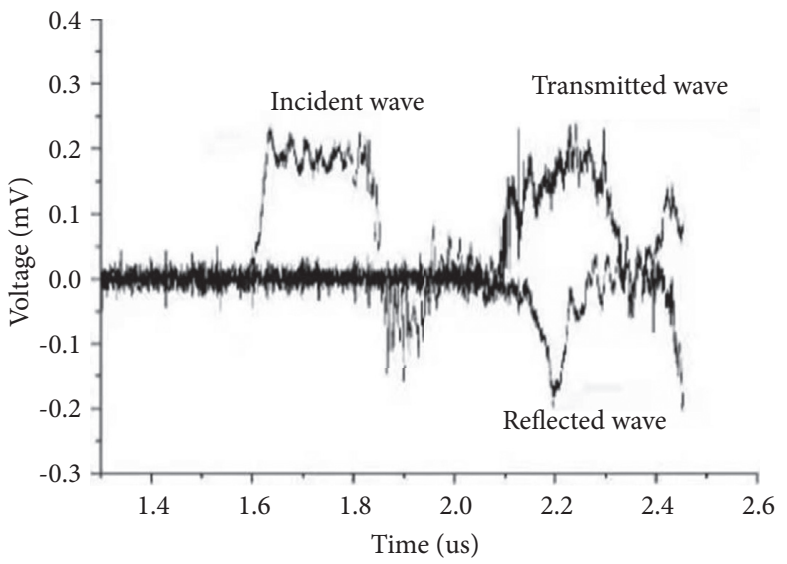

(b)

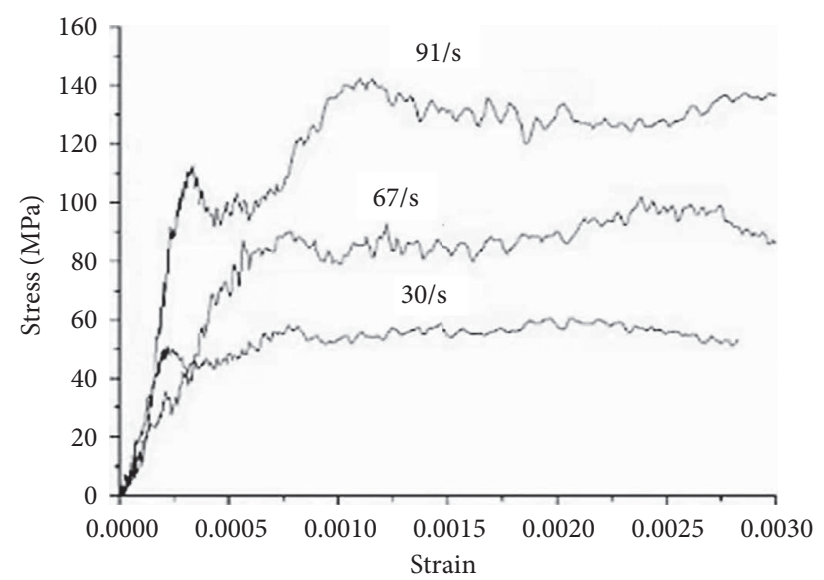

(c)

Figure 3: Voltage-time and stress-strain curves of desert sand concrete. (a) The strain rate of 29/s (M1). (b) The strain rate of 30/s (M6). (c) Stress-strain curves. 


$$
\begin{aligned}
\sigma & =-\frac{1}{2} \rho_{0} C_{0} c_{2}, \\
E_{0} & =\rho_{0} C_{0}^{2}, \\
\varepsilon & =-\frac{v_{2}}{2 C_{0}}, \\
K & =\frac{\varepsilon}{U},
\end{aligned}
$$

where $C_{0}, E_{0}, \rho_{0}$, and $v_{2}$ are stress wave speed, Young modulus, elastic bar density, and striker bar speed, respectively. Equation (3) can be achieved by combining (1) and (2). According to the corresponding relation of $K$ value, (4) is utilized to obtain the strain of the incident wave, reflected wave, and transmitted wave. In order to calculate the stress $\sigma_{(t)}$, strain $\varepsilon_{(t)}$, and strain rate $\dot{\varepsilon}_{(t)}$ of specimen, the two-wave calculation method has been used, and the formula is shown as the following equations:

$$
\begin{aligned}
& \varepsilon(t)=-\frac{2 C_{0}}{L} \varepsilon_{r}(t), \\
& \varepsilon(t)=-\frac{2 C_{0}}{L} \int_{0}^{t} \varepsilon_{r}(t) \mathrm{d} t, \\
& \sigma(t)=\frac{A_{0} E_{0}}{A} \varepsilon_{t}(t),
\end{aligned}
$$

where $\varepsilon_{r}(t), \varepsilon_{t}(t), L, A$, and $A_{0}$ are the strain of reflected wave, strain of transmitted wave, original length of specimen, original cross-sectional area of specimen, and crosssectional area of incident bar, respectively.

Based on (5), the stress-strain curve of concrete made of desert sand at various impact velocities can be obtained, as shown in Figure 3(c), and each stress-strain curve is the average value of stress-strain curves under three similar strain rates. It can be concluded that the peak stress obtains the highest value at a strain rate of $91 / \mathrm{s}$ and the lowest value at a strain rate of $30 / \mathrm{s}$. With the increase of strain rate, the peak stress of desert sand concrete increases as well. Like ordinary concrete, desert sand concrete has obvious rate effect.

Figure 4 shows the dynamic failure results of desert sand concrete and ordinary concrete specimens under different impact velocities. Impact velocities of M1 specimens were $5 \mathrm{~m} / \mathrm{s}, 17 \mathrm{~m} / \mathrm{s}$, and $22 \mathrm{~m} / \mathrm{s}$; those of M6 specimens were $5 \mathrm{~m} / \mathrm{s}$, $18 \mathrm{~m} / \mathrm{s}$, and $26 \mathrm{~m} / \mathrm{s}$; and those of OC specimens were $5 \mathrm{~m} / \mathrm{s}$, $10 \mathrm{~m} / \mathrm{s}$, and $15 \mathrm{~m} / \mathrm{s}$, respectively.

When impact velocity was $5 \mathrm{~m} / \mathrm{s}, \mathrm{M} 1, \mathrm{M} 6$, and OC specimens were not damaged. When impact velocity was $10 \mathrm{~m} / \mathrm{s}$, OC specimens were destroyed seriously, and a large number of fragments were produced. However, when impact velocity was $17 \mathrm{~m} / \mathrm{s}, \mathrm{M} 1$ specimens were generally square-shaped with partially shedding on the side surface. When impact velocity was $18 \mathrm{~m} / \mathrm{s}$, M6 specimens were cone-shaped with a large amount of shedding at the top and side. The damage degree of OC specimens was more serious when the impact velocity was
$10 \mathrm{~m} / \mathrm{s}$ than that of $15 \mathrm{~m} / \mathrm{s}$. In addition, when the impact velocity was $15 \mathrm{~m} / \mathrm{s}$, the number of fragments was more than that of $10 \mathrm{~m} / \mathrm{s}$ as shown in Figure 4 . According to the above phenomena, the following conclusions can be drawn:

(1) With impact velocity increasing, the fragments of desert sand concrete change from intact to larger pieces and small pieces. This is because under low strain rate, some microcracks have enough time to nucleate and the thus the destroyed fragments are large, but under the high strain rate, the stress increases too fast, and most microcracks are developed to nucleate at the same time, resulting in more small fragments.

(2) When impact velocity was $10 \mathrm{~m} / \mathrm{s}$, the ordinary concrete is destroyed completely, while the desert sand concrete still maintains the cone shape at $18 \mathrm{~m} /$ s. To some extent, the impact resistance of desert sand concrete is better than that of ordinary concrete.

\section{Finite Element Analysis of Dynamic Mechanical Properties of Desert Sand Concrete}

3.1. Finite Model. More and more researchers pay attention to the effect of gradation on the mechanical properties of concrete. In order to study the failure mode of different concrete, numerical simulation method of desert sand concrete, single-graded concrete, and two-graded concrete is the same. In the numerical simulation, the size range of the coarse aggregate of single-graded concrete and desert sand concrete is $5 \sim 20 \mathrm{~mm}$, and the maximum particle size is $20 \mathrm{~mm}$; the size ranges of the coarse aggregate of two-graded concrete are $5 \sim 20 \mathrm{~mm}$ and $20 \sim 40 \mathrm{~mm}$, and the maximum particle size is $40 \mathrm{~mm}$. The Explicit 2D Solid (PLANE162) element in ANSYS/LS-DYNA software is used to establish a two-dimensional finite element model of concrete. The concrete is considered as a two-phase composite which is composed of coarse aggregate and cement mortar. In order to simplify the calculation, we assume that the shape of coarse aggregate is round. Hou [48] proposed that the shape of aggregate has little influence on the mechanical properties of concrete. Therefore, the aggregate used in this test is round coarse aggregate. The number of coarse aggregates is calculated based on Fuller's graded curve [49] and Walraven's function [50], and a random distribution program of round coarse aggregate is designed to generate the coarse aggregate by ANSYS/APDL language [51]. Finite models of desert sand concrete and single-graded concrete are all chosen cylinder specimens with diameter of $74 \mathrm{~mm}$ and height of $70 \mathrm{~mm}$. The finite element model consists of three parts: the upper and lower parts are two rectangle rigid plates, and the middle part is concrete specimen. The upper part plays the role of an actuator which exerts different impact velocities on the concrete specimen. The lower part is fixed, providing a certain restraint to support the specimen. The free mesh method [52] is used for the grid divisions of coarse aggregate and cement mortar, and the mapping grid 


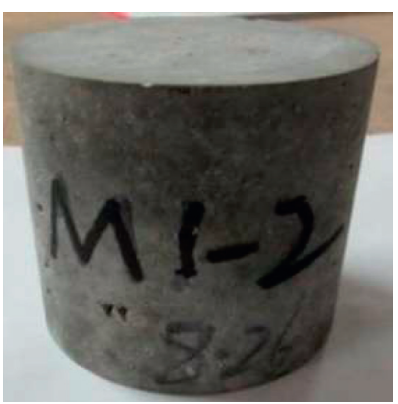

(a)

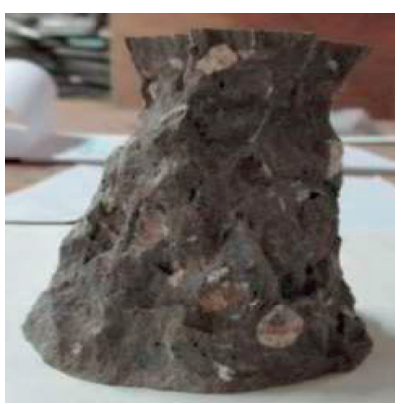

(e)

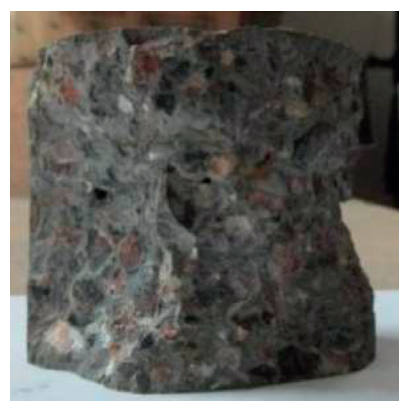

(b)

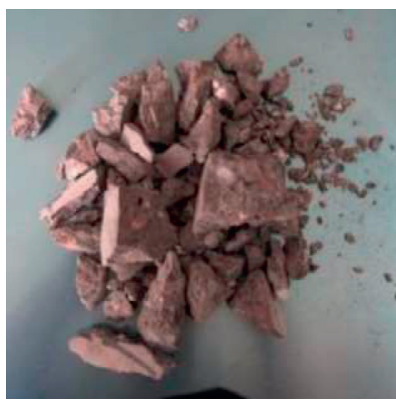

(f)

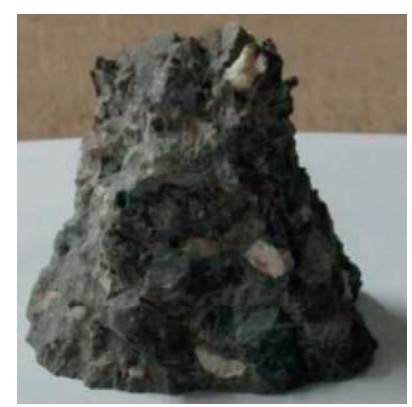

(c)

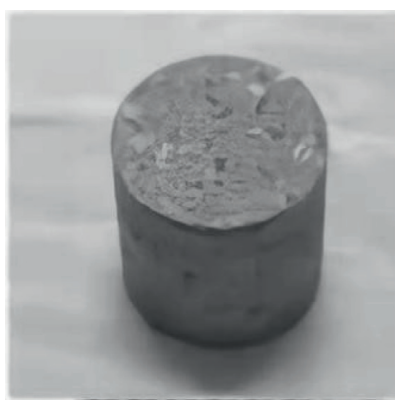

(g)

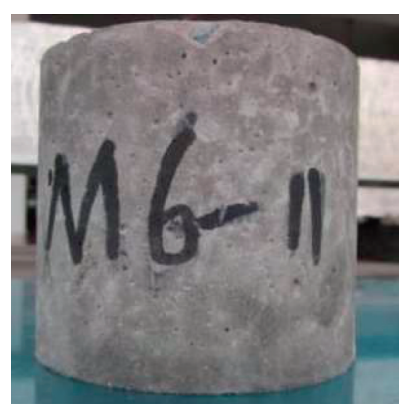

(d)

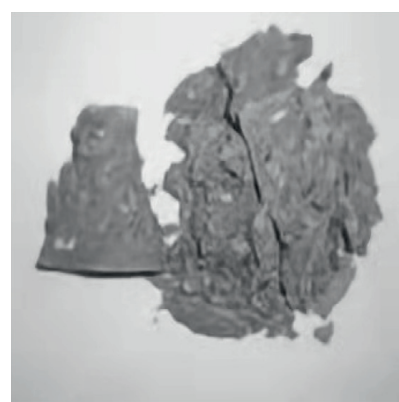

(h)

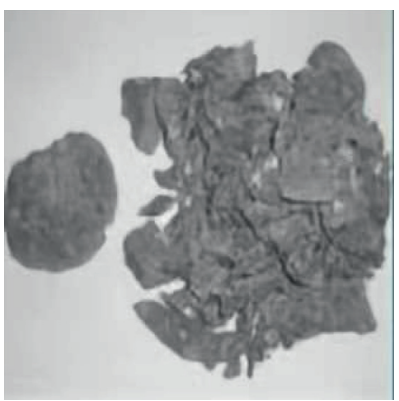

(i)

FIgure 4: Destruction results of concrete specimens under different impact velocities (74 mm diameter, $70 \mathrm{~mm}$ height cylinder). M1: (a) $5 \mathrm{~m} / \mathrm{s}$, (b) $17 \mathrm{~m} / \mathrm{s}$, and (c) $22 \mathrm{~m} / \mathrm{s}$. M6: (d) $5 \mathrm{~m} / \mathrm{s}$, (e) $18 \mathrm{~m} / \mathrm{s}$, and (f) $26 \mathrm{~m} / \mathrm{s}$. OC: (g) $5 \mathrm{~m} / \mathrm{s}$, (h) $10 \mathrm{~m} / \mathrm{s}$, and (i) $15 \mathrm{~m} / \mathrm{s}$.

method [53] is used for the grid divisions of the upper and lower rectangle rigid plates. The number of grid elements directly affects the accuracy and computation time of computer calculation results. Thus, the size of the grid elements is chosen as $2 \mathrm{~mm}$. Finite element models of desert sand concrete and single-graded concrete are shown in Figures 5(a) and 5(b), respectively.

\subsection{Constitutive Model and Parameter Selection.} Dynamic constitutive model of concrete is the theoretical basis for studying the dynamic damage mechanism of concrete. In this paper, HJC model is chosen as the constitutive model for coarse aggregate and cement mortar. The HJC constitutive model is a concrete rate-related damage constitutive model, which fully considers the large deformation of concrete materials under high strain rate. It can better describe the mechanical behavior of high-speed impact and projectile penetration concrete, including damage equation, yield surface equation, and state equation. Therefore, it is the most commonly used constitutive model for studying dynamic mechanical properties of concrete. There are three main methods to determine the parameters of the HJC constitutive model. One is to use the data in literature for reference, generally applying the original data of the model or making slight adjustments. The second one is to obtain the parameters according to empirical formulas. The third one is determining these parameters through experiments [54]. In this study, the model parameters of desert sand concrete, single-graded concrete, and two-graded concrete are all obtained by fitting the experimental data and referring to literature. The parameters for cement mortar and coarse aggregate of desert sand concrete, single-graded concrete, and two-graded concrete are listed in Tables 5 and 6, respectively.

The simulated result of peak stress of desert sand concrete compared with the experimental result is given in Figure $6(\mathrm{a})$. When impact velocity is $10 \mathrm{~m} / \mathrm{s}, 15 \mathrm{~m} / \mathrm{s}$, and $18 \mathrm{~m} / \mathrm{s}$, compared with the experimental results of the peak 


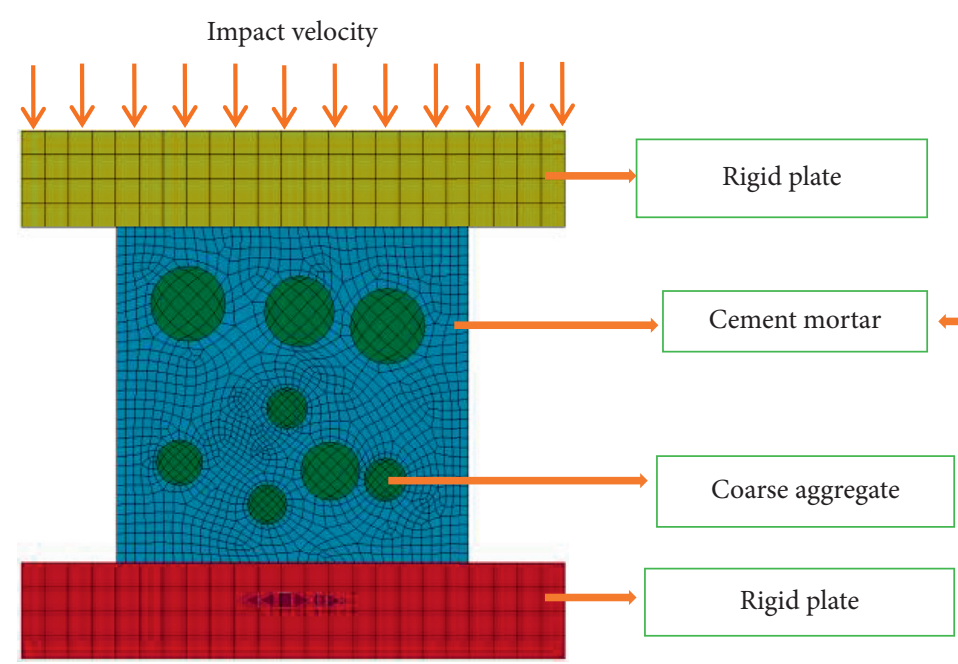

(a)

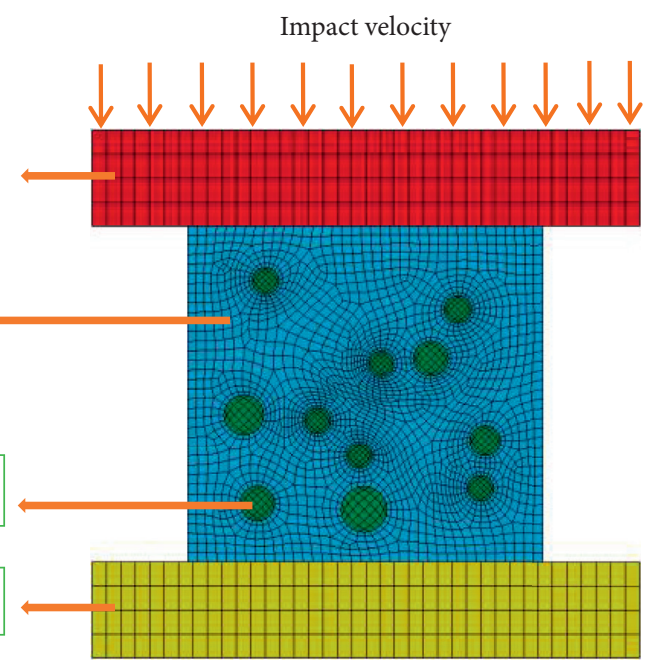

(b)

Figure 5: Finite element models. (a) Desert sand concrete. (b) Single-graded concrete.

TABLE 5: Model parameters for cement mortar.

\begin{tabular}{|c|c|c|c|c|c|c|}
\hline Parameters & $\rho_{o}\left(\mathrm{~kg} \cdot \mathrm{cm}^{-3}\right)$ & $G(\mathrm{GPa})$ & $A$ & $B$ & $f_{c}^{\prime}(\mathrm{MPa})$ & $C$ \\
\hline Single-graded concrete & 2.10 & 10.66 & 0.79 & 1.80 & 32 & 0.007 \\
\hline Two-graded concrete & 2.10 & 10.66 & 0.93 & 1.60 & 32 & 0.007 \\
\hline Desert sand concrete & 2.10 & 9.63 & 0.65 & 1.61 & 28.9 & 0.007 \\
\hline$N$ & $D_{1}$ & $\mathrm{D}_{2}$ & $\varepsilon_{f \min }$ & $P_{c}(\mathrm{MPa})$ & $P_{l}(\mathrm{MPa})$ & $\mu_{c}$ \\
\hline 0.61 & 0.04 & 1.0 & 0.01 & 10.67 & 800 & 0.0007 \\
\hline 0.86 & 0.04 & 1.0 & 0.01 & 10.67 & 1050 & 0.0007 \\
\hline 0.86 & 0.04 & 1.0 & 0.01 & 9.63 & 800 & 0.0007 \\
\hline$T(\mathrm{MPa})$ & $S_{\text {MAX }}$ & $\mu_{l}$ & $K_{1}(\mathrm{MPa})$ & $K_{2}(\mathrm{MPa})$ & $K_{3}(\mathrm{MPa})$ & $f_{s}$ \\
\hline 2.656 & 7 & 0.1 & 85 & -171 & 208 & 0.002 \\
\hline 2.656 & 7 & 0.1 & 85 & -171 & 208 & 0.002 \\
\hline 2.399 & 7 & 0.1 & 85 & -171 & 208 & 0.002 \\
\hline
\end{tabular}

TABLE 6: Model parameters for coarse aggregate.

\begin{tabular}{|c|c|c|c|c|c|c|}
\hline Parameters & $\rho_{o}\left(\mathrm{~kg} \cdot \mathrm{cm}^{-3}\right)$ & $G(\mathrm{GPa})$ & $A$ & $B$ & $f_{c}^{\prime}(\mathrm{MPa})$ & $C$ \\
\hline Single-graded concrete & 2.60 & 23 & 0.79 & 1.80 & 70 & 0.007 \\
\hline Two-graded concrete & 2.60 & 23 & 0.93 & 1.60 & 70 & 0.007 \\
\hline Desert sand concrete & 2.60 & 23 & 0.65 & 1.61 & 70 & 0.007 \\
\hline$N$ & $D_{1}$ & $\mathrm{D}_{2}$ & $\varepsilon_{f \min }$ & $P_{c}(\mathrm{MPa})$ & $P_{l}(\mathrm{MPa})$ & $\mu_{c}$ \\
\hline 0.61 & 0.04 & 1.0 & 0.01 & 23.33 & 1200 & 0.0008 \\
\hline 0.86 & 0.04 & 1.0 & 0.01 & 23.33 & 1200 & 0.0008 \\
\hline 0.86 & 0.04 & 1.0 & 0.01 & 23.33 & 800 & 0.0008 \\
\hline$T(\mathrm{MPa})$ & $S_{\text {MAX }}$ & $\mu_{l}$ & $K_{1}(\mathrm{MPa})$ & $K_{2}(\mathrm{MPa})$ & $K_{3}(\mathrm{MPa})$ & $f_{s}$ \\
\hline 5.81 & 7 & 0.012 & 85 & -171 & 208 & 0.002 \\
\hline 5.81 & 7 & 0.01 & 85 & -171 & 208 & 0.002 \\
\hline 5.81 & 7 & 0.01 & 85 & -171 & 208 & 0.002 \\
\hline
\end{tabular}

Note. $\rho_{0}$ is the density measured by the laboratory; $f_{c}^{\prime}$ and $G$ are the static uniaxial compressive strength and shear modulus, respectively; $A, B, N, C$, and $S_{\mathrm{MAx}}$ are the strength parameters; $D_{1}, D_{2}$, and $\varepsilon_{f \text { min }}$ are the damage parameters; $p_{l}, \mu_{l}, p_{c}, \mu_{c}, K_{1}, K_{2}$, and $K_{3}$ are the pressure parameters; Tis the concrete tensile strength; $f_{s}$ is equal to 0.002 as failure type parameter, which means principal strain failure mode, and the principal strain is equal to 0.002 . The parameters of HJC model are selected differently in desert sand concrete, single-graded concrete, and two-graded concrete, because of different materials and different abilities of resisting destruction.

stress of desert sand concrete, the simulated peak stress increases by $-0.9 \%,-10.7 \%$, and $6.7 \%$, respectively. Comparison of impact failure morphology of desert sand concrete between experimental and simulated results at impact velocity of $18 \mathrm{~m} / \mathrm{s}$ is shown in Figures 6(b) and 6(c). From the development trend of microcracks of the simulated 


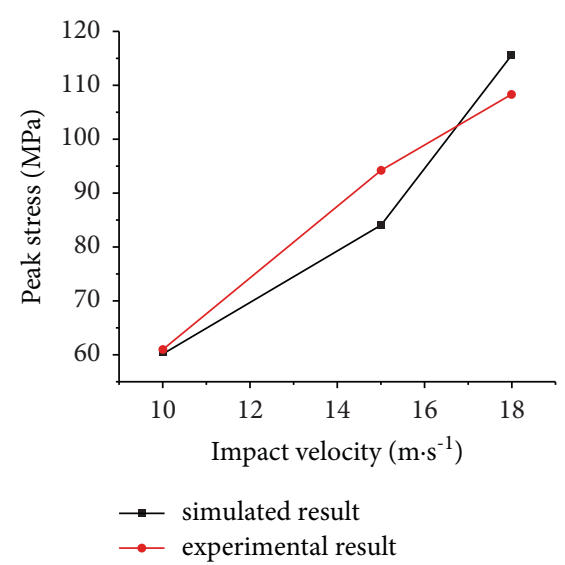

(a)
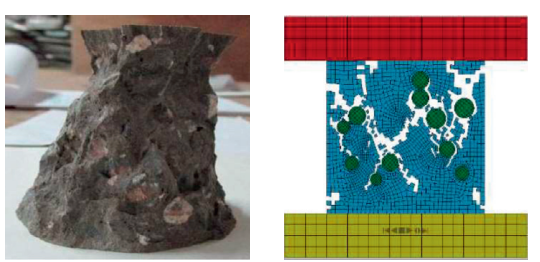

(b)

(c)

FIgURE 6: Comparison of desert sand concrete between experimental and simulated results.

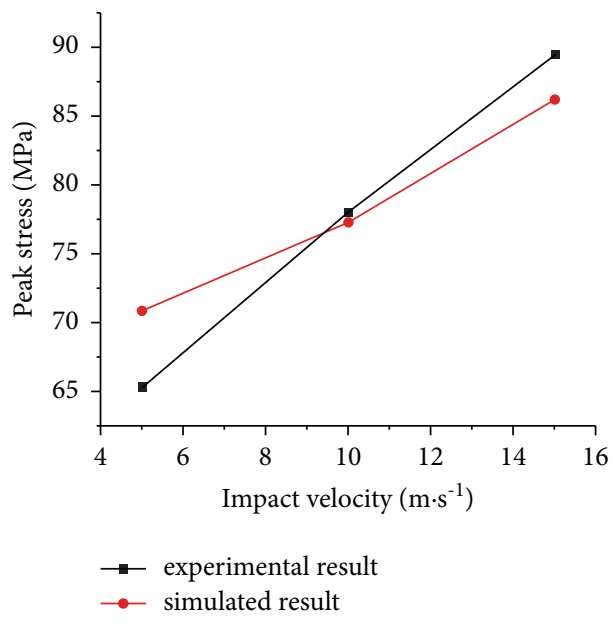

(a)
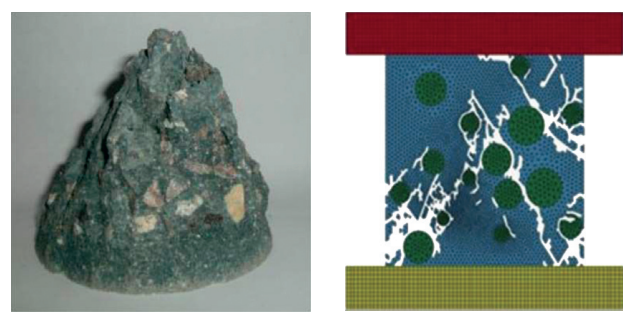

(b)

(c)

Figure 7: Comparison of single-graded concrete between experimental and simulated results.

results in Figure 6(c), it can be seen that the failure mode of desert sand concrete is a conical destructive pattern, which is similar to the experimental results in Figure 6(b).

The comparison of simulated peak stress of singlegraded concrete and the experimental result is shown in Figure $7(\mathrm{a})$. When impact velocity is $5 \mathrm{~m} / \mathrm{s}, 10 \mathrm{~m} / \mathrm{s}$, and $15 \mathrm{~m} / \mathrm{s}$, compared with the experimental results of peak stress, the simulated peak stress increases by $8.5 \%,-0.9 \%$, and $-3.62 \%$, respectively. Figures $7(\mathrm{~b})$ and $7(\mathrm{c})$ give a comparison of impact failure morphology of single-graded concrete between experimental and simulated results when impact velocity is $15 \mathrm{~m} / \mathrm{s}$. From the comparison of experimental and simulated results in Figures 7(b) and 7(c), it can be concluded that the failure mode of single-graded concrete is also conical destructive pattern, which is similar to the desert sand concrete.

As shown in Figures 6(a) and 7(a), with the impact velocity increasing gradually, the peak stress of desert sand concrete and single-graded concrete also increases, showing apparent rate effect. As shown in Figures 6(c) and 7(c), the simulated results of desert sand concrete and single-graded concrete agree well with the experimental results. Therefore, the constitutive model can be used to simulate the dynamic mechanical properties of desert sand concrete and singlegraded concrete.

\subsection{Results and Analysis}

3.3.1. Comparison of Dynamic Failure Mode of Desert Sand Concrete and Single-Graded Concrete. The failure of different materials under different stress states is different, which is related to the properties of the materials themselves $[55,56]$. The failure process of concrete activates its internal microcracks under the dynamic loading, and the microcracks expand into nucleation, growth, and merger to form macrocracks, which become the release stress zone and form cumulative damage. When the cumulative damage reaches a certain value, the strength and stiffness of the material deteriorate and ultimately make the concrete specimen fracture [57]. 
The parameters of HJC model in Tables 5 and 6 are utilized to simulate the dynamic mechanical properties of desert sand concrete and single-graded concrete. Figure 8 shows the impact failure process of desert sand concrete and single-graded concrete. When the impact velocity is $5 \mathrm{~m} / \mathrm{s}$, there are no obvious microcracks on the specimen, and the desert sand concrete is not destroyed, which is in good agreement with experimental results. However, the singlegraded concrete is destroyed when the impact velocity is $5 \mathrm{~m} / \mathrm{s}$, which is different from the experimental results. The reason might be that the actual situation of the experiment is greatly simplified in the numerical simulation, and the simulated results have great randomization. When the impact velocity is $10 \mathrm{~m} / \mathrm{s}$, there are no obvious microcracks at the beginning; with the impact time increasing gradually, many microcracks nucleate at the interface between cement mortar and coarse aggregate in the lower part of the specimen. At the same time, many new microcracks nucleate continually. The development of microcracks in desert sand concrete and single-graded concrete is similar; the microcracks first appear in the middle of the specimen, near the lateral surface, then stretch, and unite, causing the specimen fracture. When the impact velocity is $15 \mathrm{~m} / \mathrm{s}$, the microcracks of desert sand concrete nucleate in the upper part of the specimen, then stretch downward, unite, and penetrate the whole specimen, finally leading to the specimen fracture. However, microcracks of single-graded concrete first nucleate in the lower part of the specimen at the impact velocity of $15 \mathrm{~m} / \mathrm{s}$, which is essentially the same when the impact velocity is $10 \mathrm{~m} / \mathrm{s}$.

\subsubsection{Comparison of Dynamic Failure Mode of Desert Sand} Concrete and Two-Graded Concrete. There has been no reliable method to get certain data of dynamic impact experiment of two-graded concrete with SHPB experimental apparatus, as the results are too discrete. At present, means of conducing dynamic impact experiment of two-graded concrete are limited; thus, the dynamic mechanical properties of two-graded concrete can only be simulated by numerical simulation. The dynamic failure mechanism of desert sand concrete and two-graded concrete under different impact velocities $(5 \mathrm{~m} / \mathrm{s}, 10 \mathrm{~m} / \mathrm{s}$, and $15 \mathrm{~m} / \mathrm{s})$ is simulated by using the parameters of HJC model in Tables 5 and 6. The impact failure process of desert sand concrete and two-graded concrete is shown in Figure 9.

The following conclusions can be drawn in Figure 9. The dynamic failure mode of two-graded concrete is similar to single-grade concrete, when the impact velocity is $5 \mathrm{~m} / \mathrm{s}$ and $10 \mathrm{~m} / \mathrm{s}$. The dynamic failure mode of desert sand concrete had no difference compared with the results in Figure 8, in which the specimen is $74 \mathrm{~mm}$ diameter and $70 \mathrm{~mm}$ height cylinder. When the impact velocity is $15 \mathrm{~m} / \mathrm{s}$, the dynamic failure mode of the two-graded concrete is similar to that of the desert sand concrete, which is the same as the results in Figure 8. However, the dynamic failure mode of the twograded concrete is different from that of the single-graded concrete when the impact velocity is $15 \mathrm{~m} / \mathrm{s}$. Under the impact loading, the energy generated by the impact is too

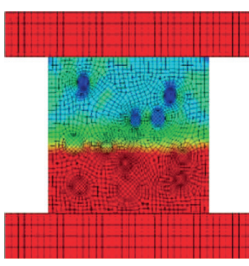

$\mathrm{t}=10.48 \mu \mathrm{s}$

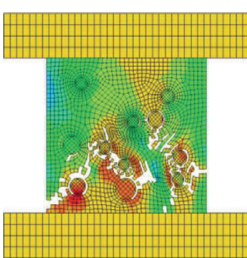

$\mathrm{t}=73.47 \mu \mathrm{s}$

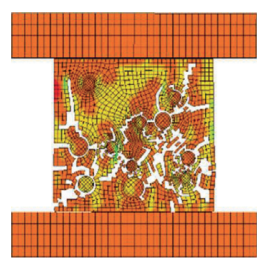

$\mathrm{t}=177.71 \mu \mathrm{s}$ (a1): Single graded concrete $\mathrm{v}=5 \mathrm{~m} / \mathrm{s}$.

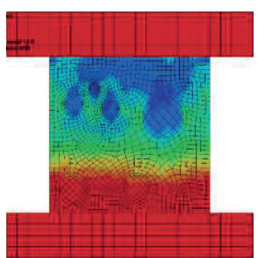

$\mathrm{t}=14 \mu \mathrm{s}$

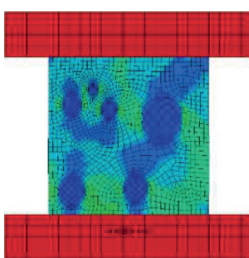

$\mathrm{t}=62 \mu \mathrm{s}$

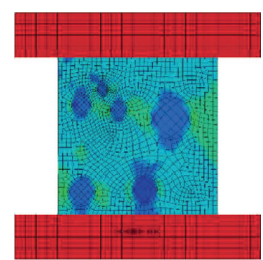

$\mathrm{t}=167 \mu \mathrm{s}$ (a2): Desert sand concrete $\mathrm{v}=5 \mathrm{~m} / \mathrm{s}$.

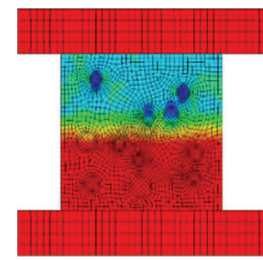

$\mathrm{t}=9.73 \mu \mathrm{s}$

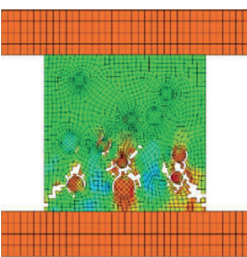

$\mathrm{t}=32.96 \mu \mathrm{s}$

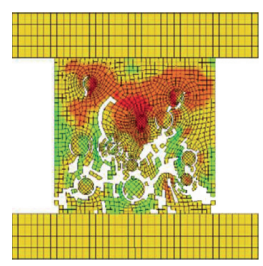

$\mathrm{t}=52.49 \mu \mathrm{s}$ (b1): Single graded concrete $v=10 \mathrm{~m} / \mathrm{s}$.

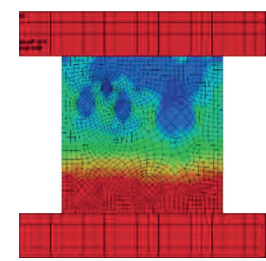

$\mathrm{t}=14 \mu \mathrm{s}$

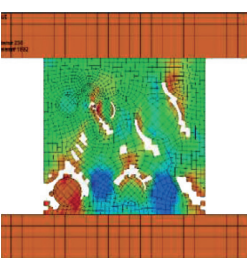

$\mathrm{t}=35 \mu \mathrm{s}$

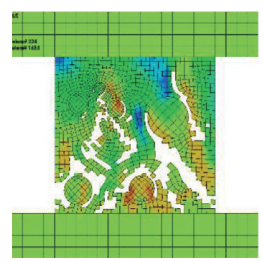

$\mathrm{t}=58 \mu \mathrm{s}$ (b2): Desert sand concrete, $v=10 \mathrm{~m} / \mathrm{s}$.

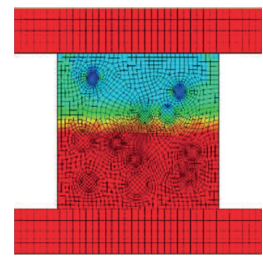

$\mathrm{t}=8.97 \mu \mathrm{s}$

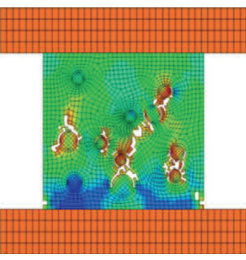

$\mathrm{t}=20.24 \mu \mathrm{s}$

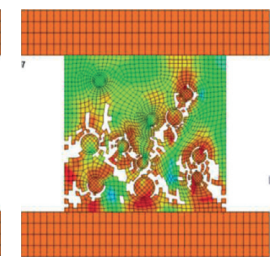

$\mathrm{t}=31.48 \mu \mathrm{s}$ (c1): Single graded concrete, $v=15 \mathrm{~m} / \mathrm{s}$.

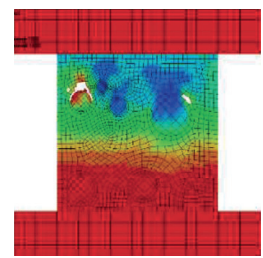

$\mathrm{t}=12 \mu \mathrm{s}$

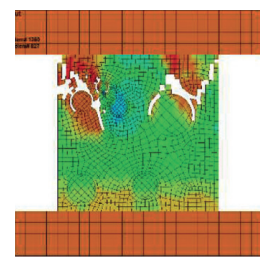

$\mathrm{t}=19 \mu \mathrm{s}$

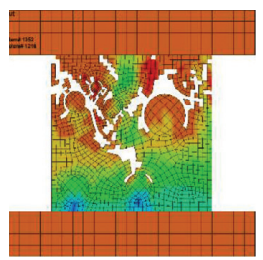

$\mathrm{t}=27 \mu \mathrm{s}$ (c2): Desert sand concrete $\mathrm{v}=15 \mathrm{~m} / \mathrm{s}$.

FIGURE 8: Impact failure process of desert sand concrete and singlegraded concrete ( $74 \mathrm{~mm}$ diameter, $70 \mathrm{~mm}$ height cylinder).

high, and the stress wave has no enough time to propagate, which causes the microcracks of concrete to first appear on the upper part of the specimen and then stretch downward 


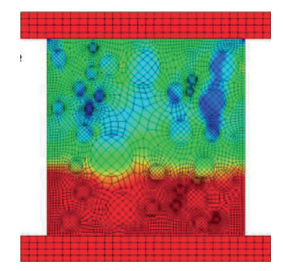

$\mathrm{t}=25 \mu \mathrm{s}$

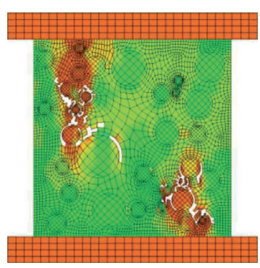

$\mathrm{t}=132 \mu \mathrm{s}$

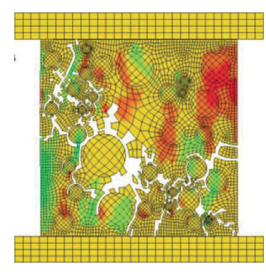

$\mathrm{t}=235 \mu \mathrm{s}$

(a1): Two grad ed concrete $\mathrm{v}=5 \mathrm{~m} / \mathrm{s}$.

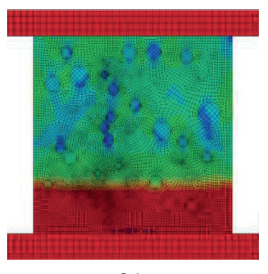

$\mathrm{t}=31 \mu \mathrm{s}$

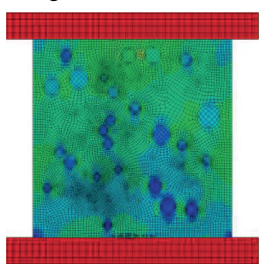

$\mathrm{t}=137 \mu \mathrm{s}$

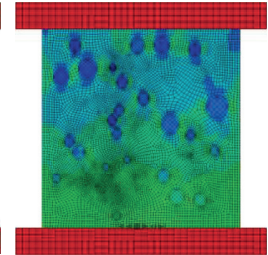

$\mathrm{t}=205 \mu \mathrm{s}$

(a2): Desert sand concrete $\mathrm{v}=5 \mathrm{~m} / \mathrm{s}$.

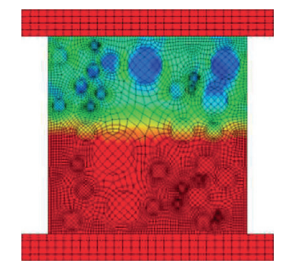

$\mathrm{t}=19 \mu \mathrm{s}$

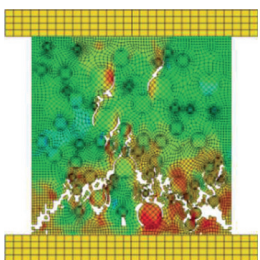

$\mathrm{t}=67.46 \mu \mathrm{s}$

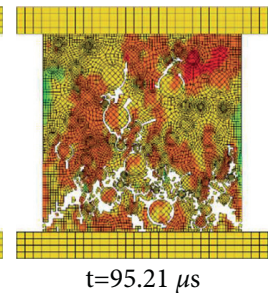

(b1): Two grad ed concrete $\mathrm{v}=10 \mathrm{~m} / \mathrm{s}$.

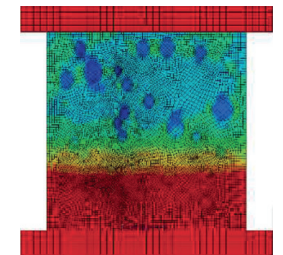

$\mathrm{t}=28 \mu \mathrm{s}$

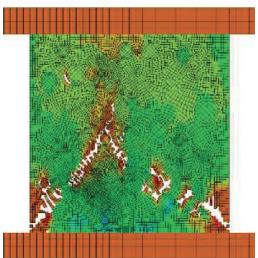

$\mathrm{t}=71 \mu \mathrm{s}$

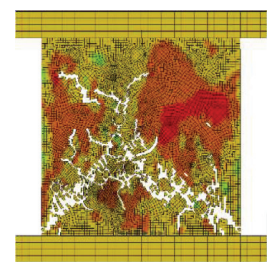

$\mathrm{t}=122 \mu \mathrm{s}$

(b2): Desert sand concrete $v=10 \mathrm{~m} / \mathrm{s}$.
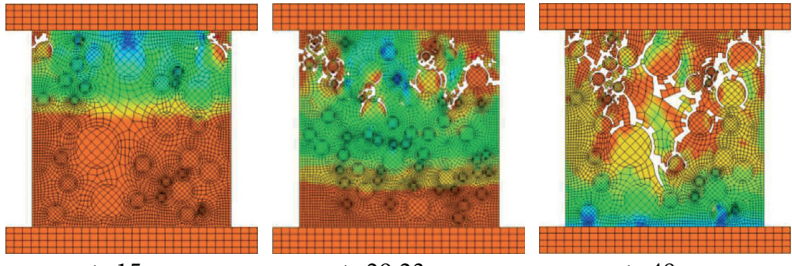

$\mathrm{t}=29.23 \mu \mathrm{s}$

$\mathrm{t}=48 \mu \mathrm{s}$

(c1): Two grad ed concrete $v=15 \mathrm{~m} / \mathrm{s}$.
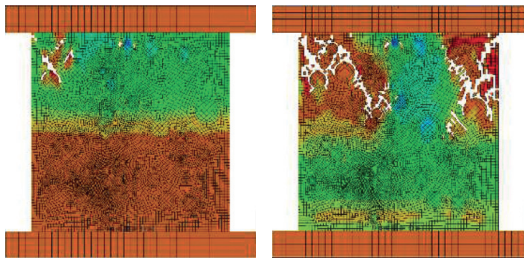

$\mathrm{t}=43 \mu \mathrm{s}$

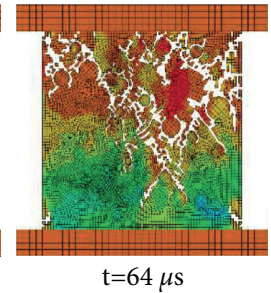

(c2): Desert sand concrete $\mathrm{v}=15 \mathrm{~m} / \mathrm{s}$.

FIGURE 9: Impact failure process of desert sand concrete and two-graded concrete $(150 \mathrm{~mm} \times 150 \mathrm{~mm} \times 150 \mathrm{~mm})$. 


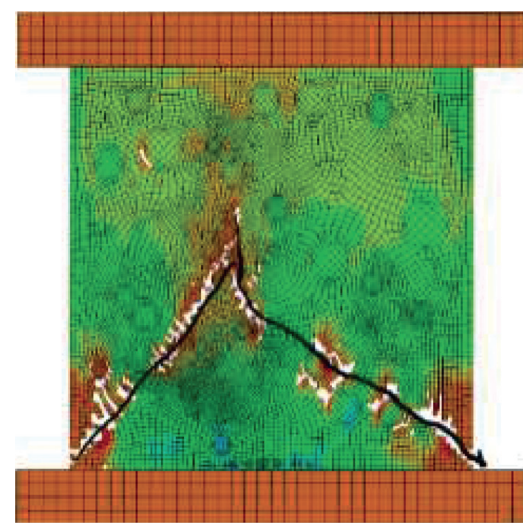

(a)

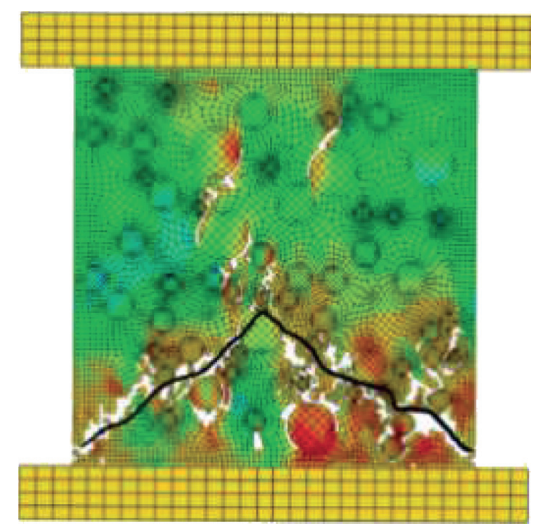

(b)

FiguRE 10: Simulated results of impact failure morphology of desert sand concrete and two-gradation concrete. (a) Desert sand concrete. (b) Two-graded concrete.

until the specimen is fractured. The failure process of concrete specimens is that the stress wave propagates from top to bottom, with repeated reflection, refraction, and superposition inside the specimens to form the microcracks, resulting in the complete fracture of the specimens.

In order to further study the dynamic failure process of desert sand concrete and two-graded concrete, Figures 10(a) and 10(b) show the simulated results of impact failure morphology of desert sand concrete and two-graded concrete, respectively. The size of specimen is $150 \mathrm{~mm} \times 150 \mathrm{~mm} \times 150 \mathrm{~mm}$. From the development trend of microcracks in Figure 10, it can be concluded that the impact failure morphology of desert sand concrete and twograded concrete still maintains the cone shape.

\section{Conclusions}

In this paper, a series of experimental studies on the impact mechanical properties of desert sand concrete and ordinary concrete were carried out, and the dynamic properties of desert sand concrete were compared with those of singlegraded concrete and two-graded concrete by numerical simulation. Through studying the dynamic impact experiments and finite element analysis of concrete, the results show the following:

(1) When the impact velocity is $10 \mathrm{~m} / \mathrm{s}$, the ordinary concrete is destroyed completely, while the desert sand concrete still maintains the cone shape at $18 \mathrm{~m} /$ $\mathrm{s}$, which indicates that the impact resistance of desert sand concrete is better than that of ordinary concrete.

(2) With the increase of impact velocity, the peak stress of desert sand concrete and ordinary concrete increases as well, showing significant rate effect.

(3) When the impact velocity is $5 \mathrm{~m} / \mathrm{s}$, the single-graded concrete and two-graded concrete are destroyed, but the desert sand concrete is not destroyed. When the impact velocity is $10 \mathrm{~m} / \mathrm{s}$, the microcracks of singlegraded concrete, two-graded concrete, and desert sand concrete all appear at the bottom of the specimen first and gradually stretch upward, resulting in specimen fracture. When the impact velocity is $15 \mathrm{~m} / \mathrm{s}$, the microcracks of the two-graded concrete and desert sand concrete first appear in the upper part of the specimen, gradually stretch downward, and ultimately lead to complete failure of the specimen, while the microcracks of the singlegraded concrete first appear in the lower part of the specimen.

(4) In numerical simulation, the dynamic failure mode of single-graded concrete, two-graded concrete, and desert sand concrete is in the form of cone-shaped failure, which is in good agreement with the experimental results.

\section{Data Availability}

The data used to support the findings of this study are included in the article.

\section{Conflicts of Interest}

The authors declare that they have no conflicts of interest.

\section{Authors' Contributions}

W. Y. and H. L. participated in conceptualization, methodology, validation, data curation, visualization, and original draft preparation. L. H. performed experimental guidance and data analysis. C. Q. and L. H. carried out theoretical analysis. All authors conducted formal analysis, reviewed and edited the manuscript, and read and agreed to the published version.

\section{Acknowledgments}

This study was financially supported by the National Natural Science Foundation of China (No. 52168034) and Ningxia Natural Science Foundation of China (No. 2020AAC03045), whose support is gratefully appreciated. 


\section{References}

[1] F. Alrshoudi, "Behaviour of Textile-reinforced concrete beams versus steel-reinforced concrete beams," Advances in Civil Engineering, vol. 2021, Article ID 6696945, 8 pages, 2021.

[2] L. Zeng, Y. Xiao, J. Chen, and Y. Chen, "Quasi-static cyclic test on a concrete-encased frame-reinforced concrete tube building model," Shock and Vibration, vol. 2018, Article ID 5643872, 14 pages, 2018.

[3] Q. Sun, N. Zhang, G. Yan, X. Zhu, X. Liu, and W. Li, "Exact dynamic characteristic analysis of steel-concrete composite continuous beams," Shock and Vibration, vol. 2021, Article ID 5577276, 2021.

[4] Q. Kong, S. Fan, X. Bai, Y. L. Mo, and G. Song, "A novel embeddable spherical smart aggregate for structural health monitoring: part I. Fabrication and electrical characterization," Smart Materials and Structures, vol. 26, no. 9, Article ID 095050, 2017.

[5] W. Li, S. C. M. Ho, D. Patil, and G. Song, "Acoustic emission monitoring and finite element analysis of debonding in fiberreinforced polymer rebar reinforced concrete," Structural Health Monitoring, vol. 16, no. 6, pp. 674-681, 2016.

[6] Y. Wang, "Study on the influence of aggregate on concrete mechanics performance," Bulletin of the Chinese Ceramic Society, vol. 34, no. 5, pp. 1329-1332, 2015.

[7] H.-X. Yang, Z.-L. Yan, and Y.-J. Liu, "Performance experimental study of shanbei desert's super-fine sand concrete," China Building Materials Science \& Technology, vol. 14, no. 1, pp. 6-8, 2005.

[8] N. Wang and B. Li, "Cooperating ratio design and research of Sahara desert sand high-strength concrete," Concrete, vol. 2014, no. 1, pp. 139-142,146, 2014.

[9] G. Zhang, J. Song, J. Yang, and X. Liu, "Performance of mortar and concrete made with a fine aggregate of desert sand," Building and Environment, vol. 41, no. 11, pp. 1478-1481, 2006.

[10] G.-X. Zhang, J.-X. Song, W.-W. Yang et al., "Effects of different desert sand on properties of cement mortar and concrete," Journal of Ningxia University (Natural Science Edition), vol. 24, no. 1, pp. 63-65, 2003.

[11] L. Haifeng, M. Jurong, W. Yiying, and N. Jianguo, "Influence of desert sand on the mechanical properties of concrete subjected to impact loading," Acta Mechanica Solida Sinica, vol. 30, no. 6, pp. 583-595, 2017.

[12] S. Zhang, K. Yuan, J. Zhang, and J. Guo, "Experimental study on performance influencing factors and reasonable mixture ratio of desert sand ceramsite lightweight aggregate concrete," Advances in Civil Engineering, vol. 2020, no. 3, pp. 1-9, 2020.

[13] J.-R. Ma, H.-F. Liu, and W.-W. Yang, "Study on the mechanical behaviors of desert sand concrete from muus desert," Science Technology and Engineering, vol. 15, no. 4, pp. 267272, 2015.

[14] H. Liu, X. Chen, J. Che, N. Liu, and M. Zhang, "Mechanical performances of concrete produced with desert sand after elevated temperature," International Journal of Concrete Structures and Materials, vol. 14, no. 1, 2020.

[15] H. F. Liu, J. R. Ma, Y. L. Chen, and D. Yang, "Mechanical properties of high strength desert sand concrete," Advanced Materials Research, vol. 1095, pp. 263-266, 2015.

[16] A. Cisse, S. Tamba, M. L. Lo, M. B. Diop, and G. Sissoko, "Contribution to improving the performance of concrete: the case of the use of desert sand of the region of Dakar," Research Journal of Environmental and Earth Sciences, vol. 4, no. 12, pp. 1071-1078, 2012.
[17] B. H. Jin and J. X. Song, "Engineering characteristics of concrete made of desert sand from maowusu sandy land," in Applied Mechanics and Materials, H. F. Liu, Ed., vol. 174177pp. 604-607, 2012.

[18] A. Rmili, M. B. Ouezdou, M. Added, and E. Ghorbel, "Incorporation of crushed sands and Tunisian desert sands in the composition of self compacting concretes Part II: SCC fresh and hardened states characteristics," International Journal of Concrete Structures and Materials, vol. 3, no. 1, pp. 11-14, 2009.

[19] Y.-Y. Wang, S.-H. Zhou, H.-F. Liu, and J.-X. Song, "Numerical simulation of dynamic failure of desert sand concrete," Concrete, vol. 2016, no. 10, pp. 69-71,76, 2016.

[20] D. A. Abrams, "Effect of rate of application of load on the compressive strength of concrete," Journal of ASTM, vol. 17, pp. 364-377, 1917.

[21] P. G. Jones, "The effect of testing speed on strength and elastic properties of concrete," Proc of Astm, vol. 36, pp. 380-391, 1936.

[22] P. R. Sparks and J. B. Menzies, "The effect of rate of loading upon the static and fatigue strengths of plain concrete in compression," International Journal of Rock Mechanics and Mining Sciences \& Geomechanics Abstracts, vol. 11, no. 8, p. A179, 1974.

[23] T. J. Holmquist, G. R. Johnson, and W. H. Cook, "A computational constitutive model for concrete subjected to large strains, high strain rates and high pressures," in Proceedings of the 14th International Symposium on Ballistics, pp. 591-600, Qubec, Canada, September 1993.

[24] S.-S. Hu, "Hopkinson pressure bar technology," Ordnance Material Science and Engineering, vol. 1991, no. 11, pp. 40-47, 1991.

[25] R. Chen, F.-Y. Lu, and K.-W. Xia, "A critical review of split hopkinson pressure bar technique," Advances in Mechanics, vol. 39, no. 5, pp. 576-587, 2009.

[26] Y.-P. Meng and S.-S. Hu, "Some problems in the test of concrete under impact compressive loading," Journal of Experimental Mechanics, vol. 2003, no. 1, pp. 108-112, 2003.

[27] X. Liu and S. Hu, "Wave propagation characteristics in cone bars used for variable cross section SHPB," Explosion \& Shock Waves, vol. 20, no. 2, pp. 110-114, 2000.

[28] Y.-Y. Mu, X.-L. Li, J.-G. Wang, and Z.-G. Leng, "Research on the mechanical properties and energy consumption transfer law of cement tailings backfill under impact load," Science of Advanced Materials, vol. 13, no. 5, pp. 889-898, 2021.

[29] D.-R. Wang and S.-S. Hu, "Study on dynamic evolution of concrete under impact load," Chinese Journal of Rock Mechanics and Engineering, vol. 22, no. 2, p. 223, 2003.

[30] S.-S. Hu and D.-R. Wang, "Dynamic constitutive relation of concrete under impact," Explosion and Shock Waves, vol. 22, no. 3, pp. 242-246, 2002.

[31] P.-Y. Lv and Y.-P. Song, "Dynamic compressive test of concrete and its constitutive model," Ocean Engineering, vol. 20, no. 2, pp. 43-48, 2002.

[32] F.-G. Zhang and E.-Z. Li, "A method to determine the parameters of the model for concrete impact and damage," Journal of Ballistics, vol. 13, no. 4, pp. 12-16, 2001.

[33] J.-G. Ning, H.-F. Liu, and L. Shang, "Dynamic mechanical properties and constitutive model of concrete under strong impact loading," Science in China, vol. 38, no. 6, pp. 759-772, 2008.

[34] J. G. Ning, L. Shang, and Y. Sun, "A viscoelastic continuum damage model for reinforced concrete subjected to shock 
loading," Key Engineering Materials, vol. 306-308, pp. 309314, 2006.

[35] J. G. Ning and F. Jiang, "Experimental study of reinforced concrete subjected to shock loading," Key Engineering Materials, vol. 326-328, pp. 1633-1636, 2006.

[36] L. Shang and J.-G. Ning, "Dynamic constitutive relationship of concrete subjected to shock load," Engineering Mechanics, vol. 22, no. 2, pp. 116-119, 2005.

[37] S. Lin, J.-G. Ning, and Y.-X. Sun, "The constitutive relationship of reinforced concrete subjected to shock loading," Acta Mechanica Solida Sinica, vol. 26, no. 2, pp. 175-181, 2005.

[38] H.-F. Liu and L. Han, "Numerical simulation research on dynamic mechanical behaviors of concrete subjected to impact loading," Chinese Journal of Solid Mechanics, vol. 36, no. 2, pp. 145-153, 2015.

[39] X.-L. Du, R.-J. Tian, Y. J. Peng, and Y. D. Tian, "Numerical simulation of concrete dynamic compressive strength under impact loading based on mesomechanics," Journal of Beijing University of Technology, vol. 35, no. 2, pp. 213-217, 2009.

[40] H. Jiang and J.-J. Wang, "Investigation on failure index of concrete in the projectile perforation simulation," Journal of Vibration and Shock, vol. 28, no. 8, pp. 30-34, 2009.

[41] C.-X. Li, "Influence of coarse aggregate size and gradation on concrete performance," Ready-mixed Concrete, vol. 6, pp. 67-68, 2012.

[42] H.-F. Liu, Y.-Y. Wang, and J.-X. Song, "Numerical simulation of dynamic mechanical behaviors of deserts and concrete," Journal of Hydraulic Engineering, vol. 47, no. 8, pp. 493-500, 2016.

[43] H.-F. Liu and L. Han, "Numerical simulation of dynamic mechanical behavior of concrete with two-dimensional random distribution of coarse aggregate," Chinese Journal of High Pressure Physics, vol. 30, no. 3, pp. 191-199, 2016.

[44] China Academy of Building Sciences, Specification for Mix Proportion Design of Ordinary concrete JGJ55-2011, China Architecture\& Building Press, Beijing, China, 2011.

[45] G. T. Gray, "Classic split Hopkinson pressure bar testing," ASM handbook, vol. 8, pp. 462-476, 2000.

[46] J.-G. Wang, T. Zuo, X.-L. Li, Z.-H. Tao, and J. Ma, "Study on the fractal characteristics of the pomegranate biotite schist under impact loading," Geofluids, Article ID 1570160, 2021.

[47] Z. Zhang, Q. Qian, H. Wang, Y. Huang, J. Wang, and H. Liu, "Study on the dynamic mechanical properties of metamorphic limestone under impact loading," Lithosphere, vol. 2021, Article ID 8403502, 2021.

[48] Y.-X. Hou, "Mesoscopic simulation of mechanical properties for reinforced concrete,", Dalian University of Technology, 2010.

[49] W. B. Fuller and S. E. Thompson, "The laws of proportioning concrete," Transactions of the American Society of Civil Engineers, vol. 59, no. 2, pp. 67-143, 1907.

[50] J. C. Walraven and H. W. Reinhardt, "Concrete mechanics. Part A: theory and experiments on the mechanical behavior of cracks in plain and reinforced concrete subjected to shear loading," Nasa Sti/recon Technical Report N, vol. 82, 1981.

[51] H.-F. Liu and Q.-L. Chen, "Numerical simulation of dynamic mechanical properties of two-gradation concrete with random distribution of coarse aggregate," Science Technology \& Engineering, vol. 17, pp. 6-10, 2017.

[52] X.-L. Ye and Y.-J. Shi, "Application example of ANSYS engineering analysis software," Tsinghua University Press, 2003.

[53] H.-F. Ma, S.-Z. Mi, and H.-Q. Chen, "A generating approach of random convex polygon aggregate model," Journal of
China Institute of Water Resources and Hydropower Research, vol. 4, no. 3, pp. 196-201, 2006.

[54] Q.-L. Chen, "Two-dimensional numerical simulation of $d y$ namic mechanical behavior of two-gradation coarse aggregate random distributing on concrete," Ningxia University, Yinchuan, China, 2017.

[55] S. -F. Wang, L.-C. Sun, X.-B. Li et al., "Experimental investigation of cuttability improvement for hard rock fragmentation using conical cutter," International Journal of Geomechanics, vol. 21, no. 2, Article ID 06020039, 2021.

[56] S.-F. Wang, Y. Tang, and S.-Y. Wang, "Influence of brittleness and confining stress on rockcuttability based on rock indentation tests," Journal of Central South University, vol. 28, no. 9, pp. 2786-2800, 2021.

[57] H. -F. Liu, H. -Y. Liu, and W. -D. Song, "Impact fracture behavior of concrete materials," Science in China, vol. 39, no. 9, pp. 1231-1240, 2009. 